Article

\title{
Crosstalk Influence between P38MAPK and Autophagy on Mitochondria-Mediated Apoptosis Induced by Anti-Fas Antibody/Actinomycin D in Human Hepatoma Bel-7402 Cells
}

\author{
Yu Wang ${ }^{1}$, Chunhui Xia ${ }^{2, *}$, Yanxin Lv ${ }^{1}$, Chengjun Li ${ }^{1}$, Qingbu Mei ${ }^{1}$, Hongmei $\mathrm{Li}^{2}$, \\ Haijun Wang ${ }^{2}$ and Shuang $\mathrm{Li}^{2}$ \\ 1 Basic Medicine Department, Qiqihar Medical University, Qiqihar 161006, China; wyfr1970@126.com (Y.W.); \\ 18745230613@sina.cn (Y.L.); lichengjun@tom.com (C.L.); mei123456@tom.com (Q.M.) \\ 2 Pharmacy Department, Qiqihar Medical University, Qiqihar 161006, China; lihongmei1969@sina.com (H.L.); \\ qmuhjwang@163.com (H.W.); lishuang@163.com (S.L.) \\ * Correspondence: chunhuixia1969@sohu.com; Tel.: +86-0452-2663-152
}

Received: 25 September 2017; Accepted: 2 October 2017; Published: 17 October 2017

\begin{abstract}
Our previous study indicated that anti-Fas antibody/actinomycin D (AF/AD) induced apoptosis of human hepatocellular carcinoma Bel-7402 cells; however, crosstalk influence between P38MAPK and autophagy on mitochondria-mediated apoptosis induced by AF/AD in Bel-7402 cells remains unclear. Therefore, effect of AF/AD on apoptosis, autophagy, phosphorylated-P38MAPK (p-P38MAPK), and membrane potential $(\triangle \Psi \mathrm{m})$ with or without the P38MAPK inhibitor SB203580 or the autophagy inhibitor 3-methyladenine (3-MA) in Bel-7402 cells was investigated in the present study. The results showed that AF/AD resulted in induction of apoptosis concomitant with autophagy, upregulation of p-P38MAPK and autophagy-associated gene proteins (Atg5-Atg12 protein complex, Atg7, Atg10, Beclin-1, LC3 I, and LC3 II), and downregulation of $\triangle \Psi \mathrm{m}$ in Bel-7402 cells. In contrast, SB203580 attenuated the effects of AF/AD in Bel-7402 cells. Furthermore, the findings also demonstrated that 3-MA inhibited the impact of AF/AD on autophagy, Atg5-Atg12 protein complex, Atg7, Atg10, Beclin-1, LC3 I, LC3 II, and $\triangle \Psi \mathrm{m}$, and promoted the influence of AF/AD on apoptosis and p-P38MAPK in Bel-7402 cells. Taken together, we conclude that crosstalk between P38MAPK and autophagy regulates mitochondria-mediated apoptosis induced by AF/AD in Bel-7402 cells.
\end{abstract}

Keywords: anti-Fas antibody/actinomycin D; P38MAPK; autophagy; mitochondria; apoptosis

\section{Introduction}

Apoptosis (Type I programmed cell death) and autophagy (Type II programmed cell death) are discrete cellular processes that play a crucial role during development and maintenance of tissue homeostasis. Recent studies have suggested that apoptosis and autophagy are two key pathways in treatment process of anticancer drugs [1,2]. The mitochondrion is a membrane-enclosed organelle occurring in eukaryotic cells. Accumulating evidence has demonstrated that mitochondrial membrane permeabilization is a key event in drugs-induced apoptosis and autophagy of cancer cells [3-5]. P38 mitogen-activated protein kinase (MAPK), a member of the MAPK family, plays a key regulatory role in cell proliferation, apoptosis, and autophagy. Past reports have shown that P38MAPK is a major determinant of the balance between apoptosis and autophagy triggered by drugs in cancer cells [6,7].

Anti-Fas antibody (AF) is a 40-kDa type II transmembrane protein belonging to the tumor necrosis factor family. When AF binds to a Fas receptor, it can trigger cells apoptosis [8-10]. Furthermore, actinomycin $\mathrm{D}(\mathrm{AD})$, a chemotherapy drug used in treatment of a variety of cancers, is capable of inducing cells apoptosis through binding to DNA [11-13]. 
Certain studies have revealed that FA/AD can apparently induce apoptosis in some cells [14-16]. Our previous research showed that p38MAPK regulated caspase-3 in AF/AD-induced apoptosis of human hepatocellular carcinoma Bel-7402 cells [17]. However, mechanisms of AF/AD-induced apoptosis of Bel-7402 cells have not been fully clarified. The aim of this study was to investigate crosstalk influence between P38MAPK and autophagy on mitochondria-mediated apoptosis induced by AF/AD in Bel-7402 cells. The results indicate that crosstalk between P38MAPK and autophagy might regulate mitochondria-mediated apoptosis induced by AF/AD in Bel-7402 cells.

\section{Results}

\subsection{AF/AD Induces Apoptosis Concomitant with Autophagy in Bel-7402 Cells}

To evaluate whether AF/AD induced apoptosis concomitant with autophagy in Bel-7402 cells, the occurrence of apoptosis and autophagy was detected by inverted microscope and electron microcopy assay. Compared with the control Bel-7402 cells, AF/AD-treated cells simultaneously exhibited apoptotic and autophagic characteristics such as cell shrinkage, nuclear condensation, and cytoplasmic vacuoles (Figure 1A,B). In addition, apoptosis concomitant with autophagy was further quantitated by flow cytometry analysis of annexin V-FLUOS/PI double-stained cells. Compared with the control treatment, AF/AD significantly led to an increase of apoptotic cell percentages (Figure 2).

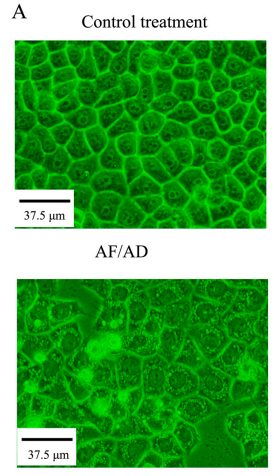

B

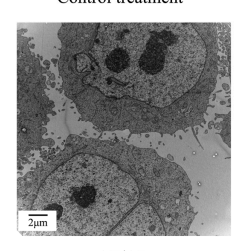

$\mathrm{AF} / \mathrm{AD}$
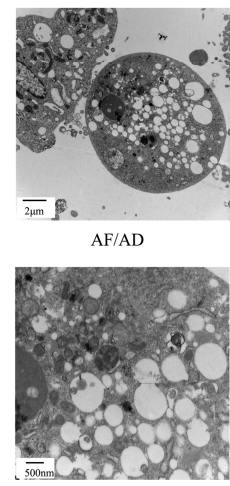

SB203580

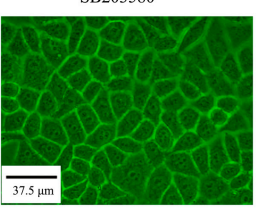

$\mathrm{AF} / \mathrm{AD}+\mathrm{SB} 203580$

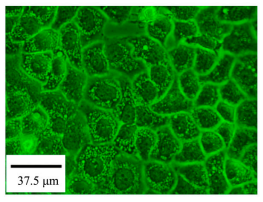

SB203580

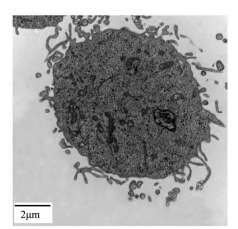

$\mathrm{AF} / \mathrm{AD}+\mathrm{SB} 203580$
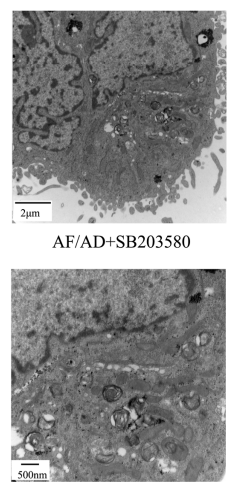

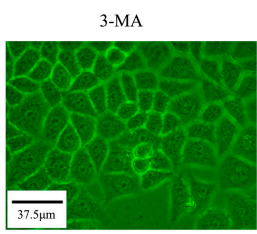

$\mathrm{AF} / \mathrm{AD}+3-\mathrm{MA}$

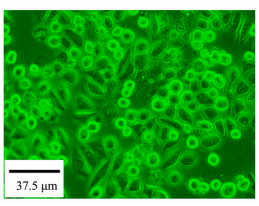

3-MA

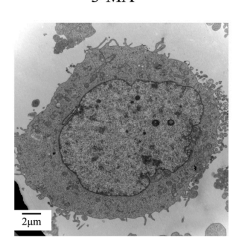

$\mathrm{AF} / \mathrm{AD}+3-\mathrm{MA}$

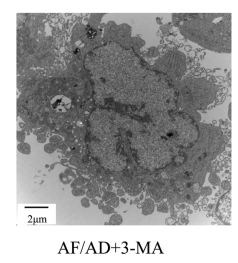

$\mathrm{AF} / \mathrm{AD}+3-\mathrm{MA}$

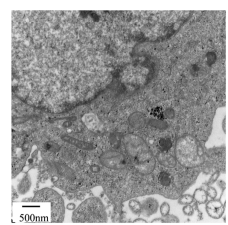

Figure 1. Effect of AF/AD on Bel-7402 cells morphology with or without SB203580 or 3-MA. Bel-7402 cells were pretreated with AF $(6 \mu \mathrm{M}) / \mathrm{AD}(20 \mu \mathrm{M})$ in the absence or presence of SB203580 $(10 \mu \mathrm{M})$ or 3-MA ( $5 \mathrm{mM})$ for $24 \mathrm{~h}$, and then cell morphology was analyzed by inverted microscope (A) and transmission electron microscopy (B). 

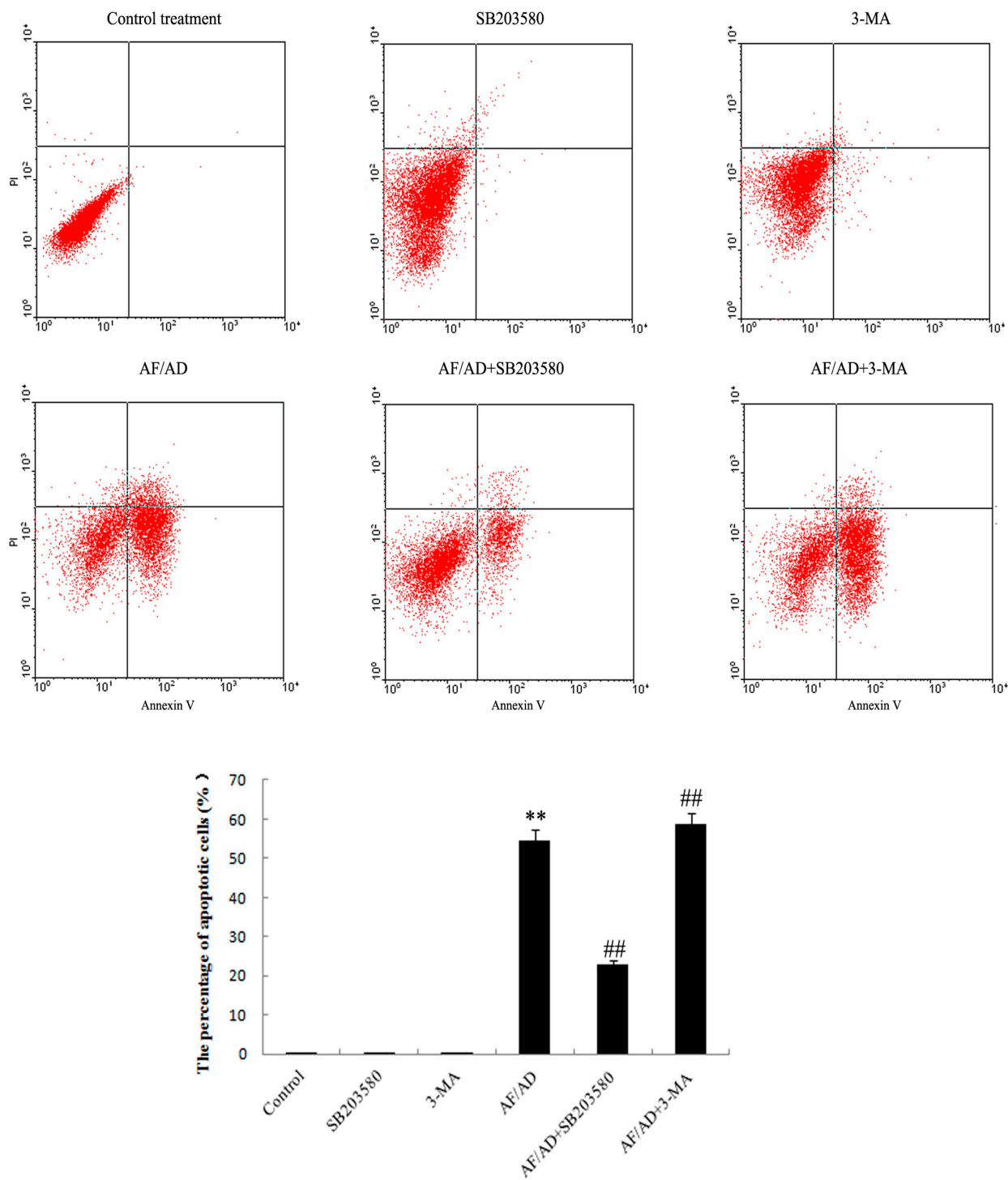

Figure 2. Effect of AF/AD on apoptosis of Bel-7402 cells with or without SB203580 or 3-MA. Bel-7402 cells were pretreated with $\mathrm{AF}(6 \mu \mathrm{M}) / \mathrm{AD}(20 \mu \mathrm{M})$ in the absence or presence of SB203580 $(10 \mu \mathrm{M})$ or 3-MA ( $5 \mathrm{mM}$ ) for $24 \mathrm{~h}$, and then the percentage of apoptotic cells was evaluated by flow cytometry analysis of annexin V-FLUOS/PI double-stained cells. Values presented are representative of three independent experiments (means \pm S.D.; ${ }^{* *} p<0.01$, compared with control treatment; ${ }^{\# \#} p<0.01$, compared with $\mathrm{AF} / \mathrm{AD}$ treatment).

To further ascertain the involvement of autophagic process in AF/AD-induced apoptosis of Bel-7402 cells, the levels of autophagy-associated genes proteins, which are called Atg proteins including Atg5-Atg12 protein complex, Atg7, Atg10, Beclin-1 (Atg-6), and LC3-I/II (Atg-8) was examined by immunoblot and immunofluorescence assay. Compared with the control treatment, AF/AD upregulated expression of Atg5-Atg12 protein complex, Atg7, Atg10, Beclin-1, LC3 I, LC3 II, green Beclin-1 immunofluorescence, and red LC3 immunofluorescence (Figure 3A,B and Figure 4A,B). Furthermore, the autophagy inhibitor 3-methyladenine (3-MA) was applied to block autophagy in Bel-7402 cells. Compared with the AF/AD treatment, 3-MA attenuated the effects of AF/AD on autophagic characteristics, Atg5-Atg12 protein complex, Atg7, Atg10, Beclin-1, LC3 I, and LC3 II (Figures 1A,B, 3A,B and 4A,B). 
A

$\begin{array}{lllllll}\mathrm{SB} 203580 & - & + & - & - & + & - \\ \text { 3-MA } & - & - & + & - & - & + \\ \mathrm{AF} / \mathrm{AD} & - & - & - & + & + & +\end{array}$

p-P38MAPK

Atg5-Atg12 protein complex

Atg7

Atg10

$\beta$-Actin
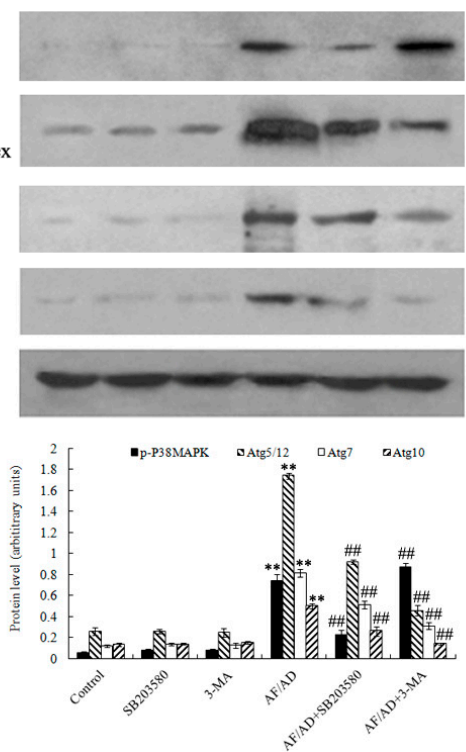

B

$\begin{array}{lllllll}\mathrm{SB} 203580 & - & + & - & - & + & - \\ \text { 3-MA } & - & - & + & - & - & + \\ \mathrm{AF} / \mathrm{AD} & - & - & - & + & + & +\end{array}$

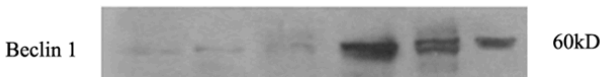

LC3 I $-18 \mathrm{kD}$

LC3 II

$\beta$-Actin

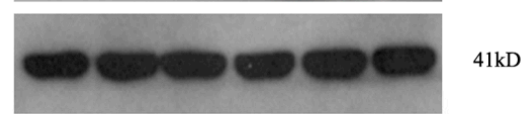

$24 \mathrm{kD}$

$41 \mathrm{kD}$

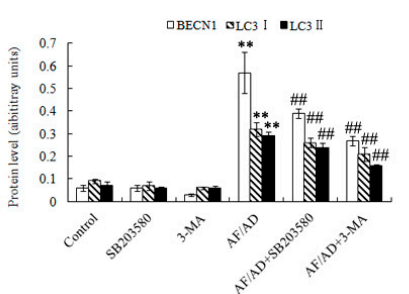

Figure 3. Effect of AF/AD on p-P38MAPK, Atg5-Atg12 protein complex, Atg7, Atg10, Beclin-1, LC3 I, and LC3 II, respectively, with or without SB203580 or 3-MA in Bel-7402 cells analyzed by immunoblot assay. Bel-7402 cells were pretreated with $\mathrm{AF}(6 \mu \mathrm{M}) / \mathrm{AD}(20 \mu \mathrm{M})$ in the absence or presence of SB203580 $(10 \mu \mathrm{M})$ or 3-MA (5 mM) for $24 \mathrm{~h}$. Expression of p-P38MAPK, Atg5-Atg12 protein complex, Atg7, and Atg10 (A), and expression of Beclin-1 and LC3 (B) were analyzed by immunoblot assay. Values presented are representative of three independent experiments (means \pm S.D.; ${ }^{* *} p<0.01$, compared with control treatment; ${ }^{\#} p<0.01$, compared with AF/AD treatment).

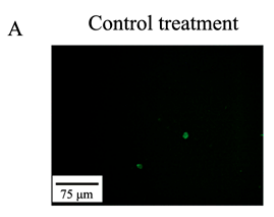

$\mathrm{AF} / \mathrm{AD}$

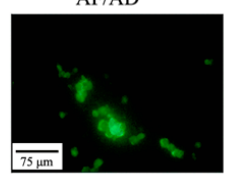

SB203580

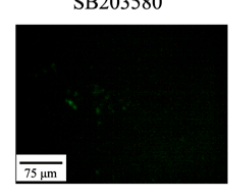

$\mathrm{AF} / \mathrm{AD}+\mathrm{SB} 203580$

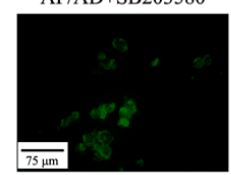

3-MA

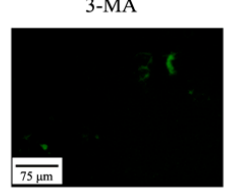

$\mathrm{AF} / \mathrm{AD}+3-\mathrm{MA}$

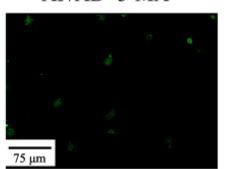

Control treatment

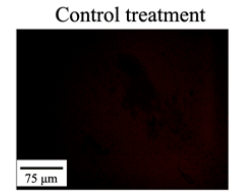

$\mathrm{AF} / \mathrm{AD}$

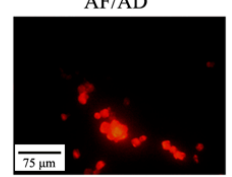

SB203580

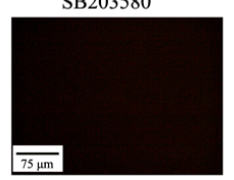

$\mathrm{AF} / \mathrm{AD}+\mathrm{SB} 203580$

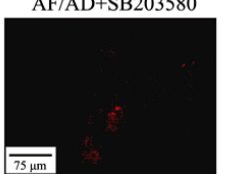

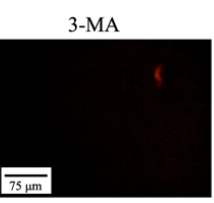

$\mathrm{AF} / \mathrm{AD}+3-\mathrm{MA}$

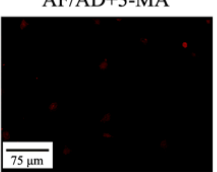

Figure 4. Effect of AF/AD on Beclin-1 and LC3, respectively, with or without SB203580 or 3-MA in Bel-7402 cells analyzed by immunofluorescence assay. Bel-7402 cells were pretreated with AF $(6 \mu \mathrm{M}) / \mathrm{AD}(20 \mu \mathrm{M})$ in the absence or presence of SB203580 $(10 \mu \mathrm{M})$ or 3-MA $(5 \mathrm{mM})$ for $24 \mathrm{~h}$. Expression of Beclin-1 (A) and LC3 (B) were analyzed by immunofluorescence assay.

\subsection{Autophagy Regulates AF/AD-Induced Apoptosis of Bel-7402 Cells}

To determine whether autophagy regulates AF/AD-induced apoptosis of Bel-7402 cells, the effect of 3-MA on apoptosis was tested. Compared with the AF/AD treatment, 3-MA promoted the AF/AD-induced apoptosis of Bel-7402 cells (Figures 1A,B and 2). 


\subsection{P38MAPK Regulates AF/AD-Induced Apoptosis Concomitant with Autophagy in Bel-7402 Cells}

To assess whether P38MAPK is involved in AF/AD-induced apoptosis concomitant with autophagy in Bel-7402 cells, the effect of AF/AD on phosphorylated-P38MAPK (p-P38MAPK) with or without the P38MAPK inhibitor SB203580 was investigated by immunoblot assay. Compared with the control treatment, AF/AD activated P38MAPK (Figure 3A); however, compared with the AF/AD treatment, SB203580 reduced the level of p-P38MAPK (Figure 3A). Moreover, SB203580 was used to further firm the regulatory role of P38MAPK during AF/AD-induced apoptosis concomitant with autophagy in Bel-7402 cells. Compared with the AF/AD treatment, SB203580 inhibited the AF/AD-induced apoptosis concomitant with autophagy in Bel-7402 cells (Figures 1A,B and 2).

\subsection{Crosstalk between P38MAPK and Autophagy Regulates AF/AD-Induced Apoptosis of Bel-7402 Cells}

To elucidate whether P38MAPK regulates autophagy, and autophagy in turn regulates P38MAPK, immunoblot and immunofluorescence assay were performed to demonstrate the effect of SB203580 on autophagy, and the effect of 3-MA on P38MAPK during AF/ AD-induced apoptosis concomitant with autophagy in Bel-7402 cells. Compared with the AF/AD treatment, 3-MA led to upregulation of p-P38MAPK (Figure 3A), and SB203580 resulted in less morphological characteristics of autophagy (Figure 1A,B), and downregulation of Atg5-Atg12 protein complex, Atg7, Atg10, Beclin-1, LC3 I, LC3 II, green Beclin-1 immunofluorescence, and red LC3 immunofluorescence (Figure 3A,B and Figure 4A,B).

\subsection{Crosstalk between P38MAPK and Autophagy Regulates Mitochondria in AF/AD-Induced Apoptosis of Bel-7402 Cells}

To explore the involvement of mitochondria in AF/AD-induced apoptosis and autophagy of Bel-7402 cells, the influence of AF/AD on mitochondrial membrane potential $(\Delta \Psi \mathrm{m})$ was evaluated by JC-I assay of fluorescence microscope and flow cytometry. Compared with the control treatment, $\mathrm{AF} / \mathrm{AD}$ cause to an increase of apoptotic cells with green fluorescence (Figure 5A), and a decrease in ratio of red/green fluorescence intensity (Figure $5 \mathrm{~B}$ ), indicating that decrease of $\Delta \Psi \mathrm{m}$ existed in AF/AD-induced apoptosis and autophagy of Bel-7402 cells. SB203580 and 3-MA were used to further clarify the regulatory effect of P38MAPK and autophagy on $\triangle \Psi \mathrm{m}$ in AF/AD-induced apoptosis of Bel-7402 cells. Compared with the AF/AD treatment, SB203580 attenuated the effect of AF/AD on $\triangle \Psi \mathrm{m}$ (Figure 5), but 3-MA strengthened the influence of AF/AD on $\Delta \Psi \mathrm{m}$ (Figure 5).

A

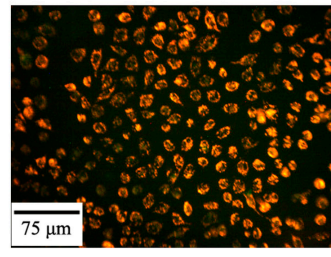

$\mathrm{AF} / \mathrm{AD}$

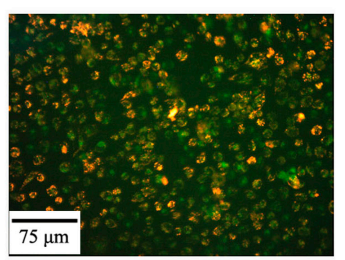

SB203580

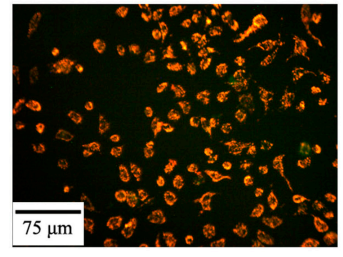

$\mathrm{AF} / \mathrm{AD}+\mathrm{SB} 203580$

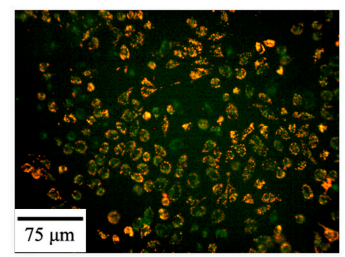

3-MA

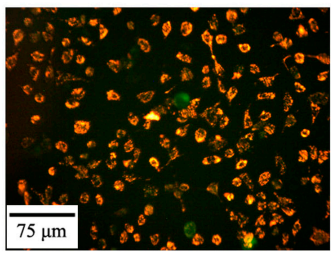

$\mathrm{AF} / \mathrm{AD}+3-\mathrm{MA}$

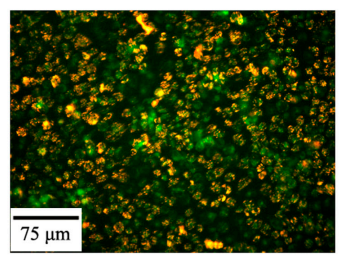

Figure 5. Cont. 
B
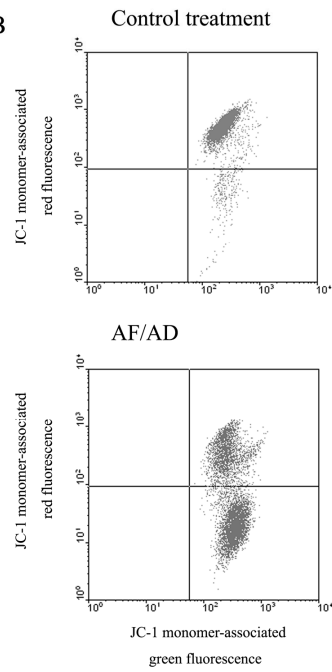

SB203580

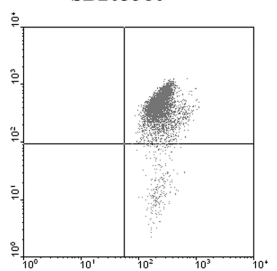

$\mathrm{AF} / \mathrm{AD}+\mathrm{SB} 203580$

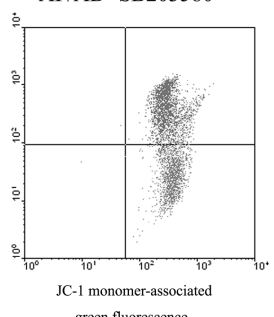

green fluorescence
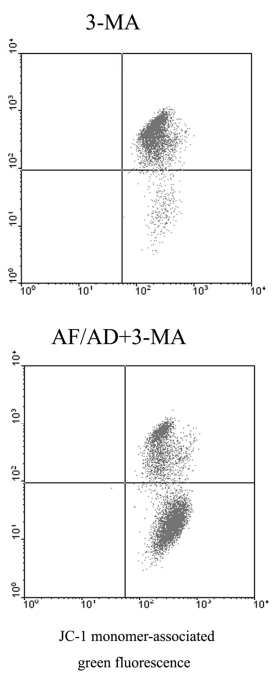

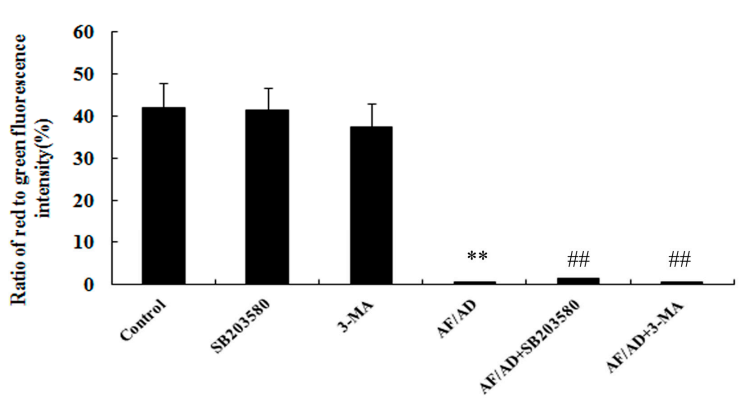

Figure 5. Effect of AF/AD on $\triangle \Psi$ m of Bel-7402 cells with or without SB203580 or 3-MA. Bel-7402 cells were pretreated with $\mathrm{AF}(6 \mu \mathrm{M}) / \mathrm{AD}(20 \mu \mathrm{M})$ in the absence or presence of SB203580 $(10 \mu \mathrm{M})$ or 3-MA ( $5 \mathrm{mM}$ ) for $24 \mathrm{~h}$. Red/green fluorescence intensity was detected by JC-1 assay of fluorescence microscope (A), and ratio of red to green fluorescence intensity was analyzed by JC-1 assay of flow cytometry (B). Values presented are representative of three independent experiments (means \pm S.D.; ** $p<0.01$, compared with control treatment; ${ }^{\# \#} p<0.01$, compared with AF/AD treatment).

\section{Discussion}

Accumulating evidence has suggested that AF/AD induces apoptosis in some cells [14-16]. We previously revealed that $\mathrm{AF}$ in the presence of $\mathrm{AD}$ induced apoptosis of Bel-7402 cells in a dose-dependent pattern [17]. However, whether AF/AD could induce apoptosis concomitant with autophagy in Bel-7402 cells is not ascertained. Therefore, we performed inverted microscope and electron microcopy assay of this, confirming that AF/AD induced apoptosis concomitant with autophagy in Bel-7402 cells.

Autophagic processes start with autophagosome formation which is regulated by Atg proteins. Atg7-mediated formation of two ubiqutin-like Atg protein conjugates, Atg5-Atg12 and LC3-I/IIphosphatidylethanolamine, function at a late step of autophagosome formation [18]. Moreover, Beclin-1and Atg-10 are essential for formation of autophagosomal structures [18]. Our data indicated that AF/AD resulted in upregulation of Atg5-Atg12 protein complex, Atg7, Atg10, Beclin-1, LC3 I, and LC3 II, but that 3-MA attenuated the effects of AF/AD on these autophagy-associated genes proteins in Bel-7402 cells, suggesting that autophagy was involved in AF/AD-induced apoptosis of Bel-7402 cells.

Several reports have revealed that autophagy plays a crucial regulatory role in drug-induced apoptosis [19-21]. However, the regulatory effect of autophagy on AF/AD-induced apoptosis of Bel-7402 cells is still not elucidated. Therefore, we studied the influence of 3-MA on AF/AD-induced apoptosis. We found that 3-MA promoted apoptosis, suggesting that autophagy regulated AF/ADinduced apoptosis of Bel-7402 cells. 
P38MAPK, which is activated by phosphorylation, has been proven to be a key regulatory protein in induction of apoptosis $[17,22,23]$. Previous studies have reported that p-P38MAPK is involved in apoptosis concomitant with autophagy in drugs-treated cancer cells [24-27]. However, the mechanism by which P38MAPK regulates AF/AD-induced apoptosis concomitant with autophagy in Bel-7402 cells is not ascertained. Therefore, we analyzed the effect of AF/AD on p-P38MAPK in combination with SB203580, and the effect of SB203580 on apoptosis concomitant with autophagy in Bel-7402 cells. We observed that AF/AD activated P38MAPK, and that SB203580 reduced the level of activated P38MAPK and protected from AF/AD-induced apoptosis concomitant with autophagy in Bel-7402 cells. These results indicate that activated P38MAPK is essential for AF/AD-induced apoptosis concomitant with autophagy in Bel-7402 cells.

Certain studies have demonstrated that P38MAPK regulates autophagy $[20,21,27,28]$, and autophagy in turn regulates P38MAPK in drugs-induced apoptosis of cancer cells [24-26]. However, whether P38MAPK and autophagy regulate each other in AF/AD-induced apoptosis of Bel-7402 cells remains unknown; therefore, the effect of SB203580 on autophagy and the effect of 3-MA on P38MAPK in AF/AD-induced apoptosis of Bel-7402 cells were examined. The results indicated that 3-MA increased the activation of P38MAPK, and that SB203580 caused less morphological characteristics of autophagy, and downregulation of Atg5-Atg12 protein complex, Atg7, Atg10, Beclin-1, LC3 I, and LC3 II. All of the above results indicate that crosstalk between P38MAPK and autophagy regulate AF/AD-induced apoptosis of Bel-7402 cells.

Early reports point out that P38MAPK and autophagy regulate mitochondria in drug-induced apoptosis of cancer cells [22,29-31]. However, it is not clear whether P38MAPK and autophagy regulate mitochondria in AF/AD-induced apoptosis of Bel-7402 cells. Therefore, the influence of AF/AD in combination with SB203580 or 3-MA on $\triangle \Psi \mathrm{m}$ was investigated. The findings demonstrated that $\mathrm{AF} / \mathrm{AD}$ resulted in the reduction of $\Delta \Psi \mathrm{m}, \mathrm{SB} 203580$ attenuated the effect of AF/AD on $\Delta \Psi \mathrm{m}$, and 3-MA strengthened the influence of $\mathrm{AF} / \mathrm{AD}$ on $\triangle \Psi \mathrm{m}$, suggesting that crosstalk between P38MAPK and autophagy regulated mitochondria in AF/AD-induced apoptosis of Bel-7402 cell.

\section{Exprimental Section}

\subsection{Materials}

Anti-phosphorylated (p)-P38MAPK antibody was purchased from Cell Signaling Technology (Danvers, MA, USA). P38MAPK inhibitor SB 203580 and actinomycin D were purchased from Merck Calbiochem (Darmstadt, Germany). Anti-Beclin-1, anti-LC3, anti-Atg5, anti-Atg7, anti-Atg10, anti-Atg12, agonistic anti-Fas, and anti- $\beta$-actin antibodies were purchased from Santa Cruz Biotechnology (Santa Cruz, CA, USA). The Annexin-V-FLUOS Staining kit was purchased from Roche (Basel, Switzerland). The 5,5',6,6' $6^{\prime}$-tetrachloro-1,1',3,3'-tetraethylbenzimidazolylcarbocyanine iodide (JC-1) staining kit was purchased from Genmed Scientifics (Wilmington, DE, USA). 3-MA, goat anti-mouse $\operatorname{IgG}(\mathrm{H}+\mathrm{L})$-FITC, and rabbit anti-goat $\operatorname{IgG}(\mathrm{H}+\mathrm{L})$-TRITC were obtained from Santa Cruz Biotechnology. All other chemicals and reagents were of analytical grade.

\subsection{Cell Culture and Treatment}

Human hepatocellular carcinoma Bel-7402 cells were offered from the Institute of Zoology, Chinese Academy of Science (Beijing, China), and cultured in DMEM medium supplemented containing 10\% fetal bovine serum, $100 \mathrm{U} / \mathrm{mL}$ penicillin, and $100 \mu \mathrm{g} / \mathrm{mL}$ streptomycin in a humidified incubator with $5.0 \% \mathrm{CO}_{2}$ at $37{ }^{\circ} \mathrm{C}$. Cells in logarithmic growth phase were incubated for $24 \mathrm{~h}$ at $37^{\circ} \mathrm{C}$, and then treated with AF/AD with or without P38 MAPK inhibitor SB203580 or autophagy inhibitor 3-MA.

\subsection{Cell Morphology Assay}

Cell morphology was assayed using inverted microscope and transmission electron microscope. For inverted microscope analysis, after AF/AD treatment in the absence or presence of SB203580 or 
3-MA, cells was observed under a DY5000X inverted microscope (Chongqing Photoelectric Instrument Co. Ltd., Chongqing, China). For transmission electron microscope analysis, after AF/AD treatment in the absence or presence of SB203580 or 3-MA, cells were fixed with 3\% glutaraldehyde in $0.1 \mathrm{M}$ sodium cacodylate buffer, transferred to $0.1 \mathrm{M}$ phosphate buffer, and then postfixed with $1 \%$ osmium tetroxide in Scollidine. After gradient dehydration in ethanol and acetone, the cells transferred to propylene oxide were embedded in Epon 812. Semi thin sections stained with 1\% methylene blue were sectioned into ultrathin slices. Afterward, ultrathin slices were contrasted with uranyl acetate and lead citrate, and detected under a HT7700 transmission electron microscope (Hitachi, Tokyo, Japan).

\subsection{Annexin V-FLUOS/Propidium Iodide (PI) Double-Staining Analysis of Apoptosis}

The Annexin V-FLUOS/PI apoptosis detection kit was used to detect apoptotic cells. Briefly, the harvested cells were resuspended in $100 \mu \mathrm{L}$ Annexin V binding buffer A. After addition of $2.0 \mu \mathrm{L}$ Annexin V-FLUOS and $2.0 \mu \mathrm{L} \mathrm{PI}$, the cell suspension was incubated for $5 \mathrm{~min}$ at room temperature in the dark. Afterward, $400 \mu \mathrm{L}$ binding buffer was added to the cells and $1 \times 10^{4}$ annexin V- FLUOS /PI double-stained cells for apoptosis were quantitatively assayed on a FACSCAN flow cytometer (Becton Dickinson, San Jose, CA, USA) using CellQuest software. The results detected by flow cytometry are shown as annexin V-FLUOS /PI plots. Apoptotic cells are indicated in right upper-lower quadrant in each plot.

\subsection{Immunoblot Assay}

After AF/AD treatment in the absence or presence of SB203580 or 3-MA, cells were lyzed in buffer solution containing $25 \mathrm{mM}$ 4-(2-hydroxyethyl)-1-piperazineethanesulfonic acid ( $\mathrm{pH} 7.5$ ), $0.3 \mathrm{M} \mathrm{NaCl}, 1.5 \mathrm{mM} \mathrm{MgCl} 2,0.2 \mathrm{mM}$ ethylenediaminetetraacetic acid, $0.1 \%$ Triton X-100, $20 \mathrm{mM}$ $\beta$-glycerophosphate, $0.5 \mathrm{mM}$ dithiothreitol, $1.0 \mathrm{mM}$ sodium orthovanadate, $0.1 \mathrm{mM}$ okadaic acid, and $1.0 \mathrm{mM}$ phenylmethylsulfonyl fluoride. Equal amounts of lysate were resolved by sodium dodecyl sulfate-polyacrylamide gel electrophoresis (SDS-PAGE) and transferred to polyvinylidene fluoride membranes. After blocking, the blots were incubated with specific primary antibodies (anti-phos-P38MAPK, anti-Atg5, anti-Atg7, anti-Atg10, anti-Atg12, Anti-Beclin-1, and anti-LC3 antibodies) overnight at $4{ }^{\circ} \mathrm{C}$ and further incubated for $1 \mathrm{~h}$ with horseradish peroxidase-linked secondary antibodies. Proteins were visualized using an enhanced chemiluminescence kit with Lumino Image Analyzer (Founder, Beijing, China). All densitometric quantifications of protein levels were made relative to $\beta$-Actin and expressed in arbitrary units.

\subsection{Immunofluorescence Assay of Beclin-1 and LC3}

After AF/AD treatment in the absence or presence of SB203580 or 3-MA, cells were incubated for $1 \mathrm{~h}$ with a 1:500 dilution of specific primary antibody (anti-Beclin-1, anti-LC3,) and further incubated for $1 \mathrm{~h}$ with a 1:2000 dilution of goat anti-mouse $\operatorname{IgG}(\mathrm{H}+\mathrm{L})-\mathrm{FITC}$ (for Beclin-1), rabbit anti-goat IgG(H+L)-TRITC (for LC3) as a secondary antibody. Fluorescence in cells was observed under a DY5000X fluorescence microscope (Chongqing Photoelectric Instrument Co. Ltd., Chongqing, China).

\subsection{JC-1 Assay for $\Delta \Psi m$}

The loss of $\Delta \Psi \mathrm{m}$ was detected by JC-1 assay using fluorescence microscopy and flow cytometry. For fluorescence microscopy analysis, after treatment with AF/AD in the absence or presence of $\mathrm{s}$ SB203580 or 3-MA, cells were incubated in culture medium containing $2.5 \mu \mathrm{g} / \mathrm{mL}$ JC-1 for $20 \mathrm{~min}$, and then analyzed using a DY5000X fluorescence microscope (Chongqing Photoelectric Instrument Co. Ltd., Chongqing, China). For flow cytometry analysis, after treatment with AF/AD in the absence or presence of SB203580 or 3-MA, cells were incubated in PBS containing $2.5 \mu \mathrm{g} / \mathrm{mL} \mathrm{JC-1} \mathrm{for}$ $20 \mathrm{~min}$. Approximately $1 \times 10^{4}$ cells were detected on a FACSCAN flow cytometer (Becton Dickinson, Franklin Lakes, NJ, USA) using CellQuest software. Dotplots presents the results detected by flow cytometry. The shift down of fluorescence from red to green indicates the loss of the $\Delta \Psi \mathrm{m}$ in each plots. 


\subsection{Statistical Analyses}

All data are means \pm S.D. from three independent experiments, and analyzed using an analysis of variance (ANOVA). $p$ value less than 0.05 was considered significant and $P$ value less than 0.01 was considered highly significant in all cases. SPSS 18.0 software (SPSS Inc., Chicago, IL, USA) was use to perform statistical analyses.

\section{Conclusions}

In the present study, we found that $\mathrm{AF} / \mathrm{AD}$ resulted in apoptosis concomitant with autophagy, upregulation of p-P38MAPK, and autophagy-associated genes proteins (Atg5-Atg12 protein complex, Atg7, Atg10, Beclin-1, LC3 I, and LC3 II) and downregulation of $\Delta \Psi \mathrm{m}$; that SB203580 attenuated the effects of $\mathrm{AF} / \mathrm{AD}$; and that 3-MA inhibited the impact of AF/AD on autophagy, Atg5-Atg12 protein complex, Atg7, Atg10, Beclin-1, LC3 I, LC3 II, and $\triangle \Psi \mathrm{m}$, and promoted the influence of $\mathrm{AF} / \mathrm{AD}$ on apoptosis and p-P38MAPK in Bel-7402 cells. Taken together, we conclude that crosstalk between P38MAPK and autophagy regulates mitochondria-mediated apoptosis induced by AF/AD in Bel-7402 cells.

Acknowledgments: The project was financially supported by the Natural Science Foundation of Heilongjiang Province (No. C201319).

Author Contributions: C.X. designed the experiments and wrote the paper; Y.W., Y.L., C.L. and S.L. performed the experiments; Q.M., H.L. and H.W. revised the paper.

Conflicts of Interest: The authors report no conflict of interest.

\section{References}

1. Zheng, N.; Liu, L.; Liu, W.W.; Li, F.; Hayashi, T.; Tashiro, S.I.; Onodera, S.; Ikejima, T. Crosstalk of ROS/RNS and autophagy in silibinin-induced apoptosis of MCF-7 human breast cancer cells in vitro. Acta Pharmacol. Sin. 2017, 38, 277-289. [CrossRef] [PubMed]

2. Bastola, T.; An, R.B.; Kim, Y.C.; Kim, J.; Seo, J. Cearoin Induces Autophagy, ERK Activation and Apoptosis via ROS Generation in SH-SY5Y Neuroblastoma Cells. Molecules 2017, 22, 242. [CrossRef] [PubMed]

3. Chen, L.; Li, G.; Peng, F.; Jie, X.; Dongye, G.; Cai, K.; Feng, R.; Li, B.; Zeng, Q.; Lun, K.; et al. The induction of autophagy against mitochondria-mediated apoptosis in lung cancer cells by a ruthenium (II) imidazole complex. Oncotarget 2016, 7, 80716-80734.

4. Wang, X.; Wei, S.; Zhao, Y.; Shi, C.; Liu, P.; Zhang, C.; Lei, Y.; Zhang, B.; Bai, B.; Huang, Y.; et al. Anti-proliferation of breast cancer cells with itraconazole: Hedgehog pathway inhibition induces apoptosis and autophagic cell death. Cancer Lett. 2017, 385, 128-136. [CrossRef] [PubMed]

5. Shao, F.Y.; Du, Z.Y.; Ma, D.L.; Chen, W.B.; Fu, W.Y.; Ruan, B.B.; Rui, W.; Zhang, J.X.; Wang, S.; Wong, N.S.; et al. $\mathrm{B} 5$, a thioredoxin reductase inhibitor, induces apoptosis in human cervical cancer cells by suppressing the thioredoxin system, disrupting mitochondrion-dependent pathways and triggeringautophagy. Oncotarget 2015, 6, 30939-30956. [CrossRef] [PubMed]

6. Zhan, Y.; Gong, K.; Chen, C.; Wang, H.; Li, W. P38 MAP kinase functions as a switch in MS-275-induced reactive oxygen species-dependent autophagy and apoptosis in human colon cancer cells. Free Radic. Biol. Med. 2012, 53, 532-543. [CrossRef] [PubMed]

7. De la Cruz-Morcillo, M.A.; Valero, M.L.; Callejas-Valera, J.L.; Arias-González, L.; Melgar-Rojas, P.; Galán-Moya, E.M.; García-Gil, E.; García-Cano, J.; Sánchez-Prieto, R. P38MAPK is a major determinant of the balance between apoptosis and autophagy triggered by 5 -fluorouracil: Implication in resistance. Oncogene 2012, 31, 1073-1085. [CrossRef] [PubMed]

8. Schmich, K.; Schlatter, R.; Corazza, N.; Sá Ferreira, K.; Ederer, M.; Brunner, T.; Borner, C.; Merfort, I. Tumor necrosis factor $\alpha$ sensitizes primary murine hepatocytes to Fas/CD95-induced apoptosis in a Bim- and Bid-dependent manner. Hepatology 2011, 53, 282-292. [CrossRef] [PubMed]

9. Qin, Y.; Auh, S.; Blokh, L.; Long, C.; Gagnon, I.; Hamann, K.J. TNF-alpha induces transient resistance to Fas-induced apoptosis in eosinophilic acute myeloid leukemia cells. Cell. Mol. Immunol. 2007, 4, 43-52. [PubMed] 
10. Nagata, S.; Golstein, P. The Fas death factor. Science 1995, 267, 1449-1456. [CrossRef] [PubMed]

11. Zajkowicz, A.; Gdowicz-Kłosok, A.; Krześniak, M.; Ścieglińska, D.; Rusin, M. Actinomycin D and nutlin-3a synergistically promote phosphorylation of p53 on serine 46 in cancer cell lines of different origin. Cell Signal. 2015, 27, 1677-1687. [CrossRef] [PubMed]

12. Choong, M.L.; Yang, H.; Lee, M.A.; Lane, D.P. Specific activation of the p53 pathway by low dose actinomycin D: A new route to p53 based cyclotherapy. Cell Cycle 2009, 8, 2810-2818. [CrossRef] [PubMed]

13. Sobell, H. Actinomycin and DNA transcription. Proc. Natl. Acad. Sci. USA 1985, 82, 5328-5331. [CrossRef] [PubMed]

14. Förster, A.; Falcone, F.H.; Gibbs, B.F.; Preussner, L.M.; Fiebig, B.S.; Altunok, H.; Seeger, J.M.; Cerny-Reiterer, S.; Rabenhorst, A.; et al. Anti-Fas/CD95 and tumor necrosis factor-related apoptosis-inducing ligand (TRAIL) differentially regulate apoptosis in normal and neoplastic human basophils. Leuk. Lymphoma 2013, 54, 835-842. [CrossRef] [PubMed]

15. Park, M.A.; Pejovic, V.; Kerisit, K.G.; Junius, S.; Thoene, J.G. Increased apoptosis in cystinotic fibroblasts and renal proximal tubule epithelial cells results from cysteinylation of protein kinase Cdelta. J. Am. Soc. Nephrol. 2006, 17, 3167-3175. [CrossRef] [PubMed]

16. Aoyama, T.; Takemura, G.; Maruyama, R.; Kosai, K.; Takahashi, T.; Koda, M.; Hayakawa, K.; Kawase, Y.; Minatoguchi, S.; Fujiwara, H. Molecular mechanisms of non-apoptosis by Fas stimulation alone versus apoptosis with an additional actinomycin D in cultured cardiomyocytes. Cardiovasc. Res. 2002, 55, 787-798. [CrossRef]

17. Wang, Y.; Sun, L.; Xia, C.; Ye, L.; Wang, B. P38MAPK Regulates Caspase-3 by Binding to Caspase-3 in Nucleus of Human Hepatoma Bel-7402 Cells during Anti-Fas Antibody- and Actinomycin D-Induced Apoptosis. Biomed. Pharmacother. 2009, 63, 343-350. [CrossRef] [PubMed]

18. Mizushima, N.; Yoshimori, T.; Ohsumi, Y. The Role of Atg Proteins in Autophagosome Formation. Annu. Rev. Cell Dev. Biol. 2011, 27, 7-32. [CrossRef] [PubMed]

19. Teng, Y.H.; Li, J.P.; Liu, S.L.; Zou, X.; Fang, L.H.; Zhou, J.Y.; Wu, J.; Xi, S.Y.; Chen, Y.; Zhang, Y.Y.; et al. Autophagy Protects from Raddeanin A-Induced Apoptosis in SGC-7901 HumanGastric Cancer Cells. Evid. Based Complement. Alternat. Med. 2016, 2016, 9406758. [CrossRef] [PubMed]

20. Yuan, L.; Wei, S.; Wang, J.; Liu, X. Isoorientin induces apoptosis and autophagy simultaneously by reactive oxygen species (ROS)-related p53, PI3K/Akt, JNK, and p38 signaling pathways in HepG2 cancer cells. J. Agric. Food Chem. 2014, 62, 5390-5400. [CrossRef] [PubMed]

21. Utaipan, T.; Athipornchai, A.; Suksamrarn, A.; Chunsrivirot, S.; Chunglok, W. Isomahanine induces endoplasmic reticulum stress and simultaneously triggers p38 MAPK-mediated apoptosis and autophagy in multidrug-resistant human oral squamous cell carcinomacells. Oncol. Rep. 2017, 37, 1243-1252. [CrossRef] [PubMed]

22. Duan, F.; Yu, Y.; Guan, R.; Xu, Z.; Liang, H.; Hong, L. Vitamin K2 Induces Mitochondria-Related Apoptosis in Human Bladder Cancer Cells via ROS and JNK/p38 MAPK Signal Pathways. PLoS ONE 2016, 11, e0161886. [CrossRef] [PubMed]

23. Beccafico, S.; Morozzi, G.; Marchetti, M.C.; Riccardi, C.; Sidoni, A.; Donato, R.; Sorci, G. Artesunate induces ROS-and p38 MAPK-mediated apoptosis and counteracts tumor growth in vivo in embryonal rhabdomyosarcoma cells. Carcinogenesis 2015, 36, 1071-1083. [CrossRef] [PubMed]

24. Xu, M.Y.; Lee, S.Y.; Kang, S.S.; Kim, Y.S. Antitumor activity of jujuboside B and the underlying mechanism via induction of apoptosis and autophagy. J. Nat. Prod. 2014, 77, 370-376. [CrossRef] [PubMed]

25. Xu, M.Y.; Lee, D.H.; Joo, E.J.; Son, K.H.; Kim, Y.S. Akebia saponin PA induces autophagic and apoptotic cell death in AGS human gastric cancer cells. Food Chem. Toxicol. 2013, 59, 703-708. [CrossRef] [PubMed]

26. Yan, Y.; Jiang, K.; Liu, P.; Zhang, X.; Dong, X.; Gao, J.; Liu, Q.; Barr, M.P.; Zhang, Q.; Hou, X.; et al. Bafilomycin A1 induces caspase-independent cell death in hepatocellular carcinoma cells via targeting of autophagy and MAPK pathways. Sci. Rep. 2016, 6, 37052. [CrossRef] [PubMed]

27. Zhong, W.; Zhu, H.; Sheng, F.; Tian, Y.; Zhou, J.; Chen, Y.; Li, S.; Lin, J. Activation of the MAPK11/12/13/14 (p38 MAPK) pathway regulates the transcription of autophagy genes in response to oxidative stress induced by a novel copper complex in HeLa cells. Autophagy 2014, 10, 1285-1300. [CrossRef] [PubMed]

28. Zhao, R.; Chen, M.; Jiang, Z.; Zhao, F.; Xi, B.; Zhang, X.; Fu, H.; Zhou, K. Platycodin-D Induced Autophagy in Non-Small Cell Lung Cancer Cells via PI3K/Akt/mTOR and MAPK Signaling Pathways. J. Cancer 2015, 6, 623-631. [CrossRef] [PubMed] 
29. Kang, N.; Wang, M.M.; Wang, Y.H.; Zhang, Z.N.; Cao, H.R.; Lv, Y.H.; Yang, Y.; Fan, P.H.; Qiu, F.; Gao, X.M. Tetrahydrocurcumin induces G2/M cell cycle arrest and apoptosis involving p38 MAPK activation in human breast cancer cells. Food Chem. Toxicol. 2014, 67, 193-200. [CrossRef] [PubMed]

30. Chen, P.; Luo, X.; Nie, P.; Wu, B.; Xu, W.; Shi, X.; Chang, H.; Li, B.; Yu, X.; Zou, Z. CQ synergistically sensitizes human colorectal cancer cells to SN-38/CPT-11 through lysosomal and mitochondrial apoptotic pathway via p53-ROS cross-talk. Free Radic. Biol. Med. 2017, 104, 280-297. [CrossRef] [PubMed]

31. Ma, J.; Meng, F.; Li, S.; Liu, L.; Zhao, L.; Liu, Y.; Hu, Y.; Li, Z.; Yao, Y.; Xi, Z.; et al. Autophagy Induction by Endothelial-Monocyte Activating Polypeptide II Contributes to the Inhibition of Malignant Biological Behaviors by the Combination of EMAP II with Rapamycin in Human Glioblastoma. Front. Mol. Neurosci. 2015, 8, 74. [CrossRef] [PubMed]

Sample Availability: Samples of the compounds are available from the authors.

(C) 2017 by the authors. Licensee MDPI, Basel, Switzerland. This article is an open access article distributed under the terms and conditions of the Creative Commons Attribution (CC BY) license (http:/ / creativecommons.org/licenses/by/4.0/). 